\title{
Milk polar lipids modulate lipid metabolism, gut permeability, and systemic inflammation in high-fat-fed C57BL/6J ob/ob mice, a model of severe obesity
}

\author{
A. L. Zhou and R. E. Ward* \\ Nutrition, Dietetics and Food Sciences, Utah State University, 8700 Old Main Hill, Logan 84322
}

\section{ABSTRACT}

Dynamic interactions between lipid metabolism, gut permeability, and systemic inflammation remain unclear in the context of obesity. Milk polar lipids, lipids derived from the milk fat globule membrane, could positively affect the aforementioned obesity-related endpoints. This study aimed to test the hypotheses that milk polar lipids will reduce gut permeability, systemic inflammation, and liver lipid levels, and differentially affect the hepatic expression of genes associated with fatty acid synthesis and cholesterol regulation in preexisting obesity. We fed 3 groups of C57BL/6J ob/ob mice $(\mathrm{n}=6$ per group) for 2 wk: (1) a modified AIN-93G diet (CO) with $34 \%$ fat by energy; (2) CO with milk gangliosides (GG) at $0.2 \mathrm{~g} / \mathrm{kg}$ of diet; and (3) $\mathrm{CO}$ with milk phospholipids (PL) at $10 \mathrm{~g} / \mathrm{kg}$ of diet. The GG and PL were provided as semi-purified concentrates and replaced $2.0 \%$ and $7.2 \%$ of dietary fat by energy. The GG and PL did not affect total food intake, weight gain, fasting glucose, or gut permeability. The PL decreased liver mass and the mesenteric fat depot compared with the $\mathrm{CO}$. The GG increased tight junction protein occludin in colon mucosa compared with the CO. The GG and PL decreased tight junction protein zonula occludens-1 in jejunum mucosa compared with the CO. Plasma endotoxin increased during the study but was unaffected by the treatments. Compared with the $\mathrm{CO}$ and GG, the PL increased plasma sphingomyelin and plasma IL-6. The GG and PL differentially regulated genes associated with lipid metabolism in the liver compared with the CO. Regarding general effects on lipid metabolism, the GG and PL decreased lipid levels in the liver and the mesenteric depot, and increased lipid levels in the plasma. Diet consumption decreased significantly when the ob/ob mice were kept in metabolic cages, which were not big enough and resulted in unwanted

Received November 6, 2018.

Accepted February 22, 2019.

*Corresponding author: robert.ward@usu.edu animal deaths. Future studies may keep this in mind and use better metabolic equipment for ob/ob mice. In conclusion, dietary milk polar lipids may have limited beneficial effects on gut barrier integrity, systemic inflammation, and lipid metabolism in the context of severe obesity.

Key words: milk polar lipids, lipid metabolism, gut permeability, inflammation

\section{INTRODUCTION}

Obesity is defined as a condition with excessive body fat that adversely affects health (Haslam and James, 2005). The pathological states associated with obesity include many comorbidities, such as leaky gut, dyslipidemia, nonalcoholic fatty liver disease, and systemic inflammation (Bullo et al., 2007; Teixeira et al., 2012). Increased gut permeability in obesity (Cani et al., 2008; Teixeira et al., 2012) results in endotoxemia, the presence of LPS in blood. Lipopolysaccharides can activate the toll-like receptor 4 (TLR4) and initiate systemic inflammation (Laugerette et al., 2012). Adipose tissue is both the source and target for proinflammatory cytokines, such as tumor necrosis factor- $\alpha$ (TNF- $\alpha)$ and IL-6 (Weisberg et al., 2003; Iyer et al., 2010). High inflammatory cytokines may alter the tight junctions (TJ) to compromise the intestinal barrier (Bruewer et al., 2003). Obesity, systemic inflammation, and increased gut permeability may generate a self-perpetuating vicious cycle (Iacono et al., 2011), in which lipid metabolism is involved. Plasma long-chain SFA activate the TLR4 and initiate IL-6 secretion (Laugerette et al., 2012). Long-chain SFA may have a synergistic effect with LPS in activating the TLR4 (Laugerette et al., 2012). Therefore, increased gut barrier permeability, endotoxemia, systemic inflammation, and lipid metabolism are complexly interrelated events in obesity.

Dietary bioactives may reduce the comorbidities of obesity. Milk polar lipids, mainly coming from the milk fat globule membrane (MFGM) and containing phospholipids (PL) and gangliosides (GG; Zhou et al., 2012), may play important roles in maintaining gastrointestinal barrier integrity and affecting systemic 
inflammation and lipid metabolism. Milk polar lipids protect gut barrier integrity in mice stressed by LPS (Snow et al., 2011). Dairy GG preserve gut integrity during LPS-induced acute inflammation in rats (Park et al., 2010). The MFGM does not affect postprandial inflammatory markers in obese or overweight subjects consuming high SFA (Rogers et al., 2017). Milk sphingomyelin lowers hepatic lipid level and lessens adipose tissue inflammation in high-fat-diet-induced obese mice (Norris et al., 2017). Dietary PL reduce liver triacylglycerols and cholesterol in rats (Cohn et al., 2008). A PL-rich MFGM extract reduces hepatic steatosis and hyperlipidemia, and positively regulates lipid metabolism genes in mice (Wat et al., 2009). Phospholipids affect liver lipid metabolism partially through the choline contributed by the phosphatidylcholine when the diets are high in sucrose, which promotes the development of fatty liver disease in rats (Bacon et al., 1984). Milk sphingolipids, including sphingomyelin and GG, reduce uptake of cholesterol (Noh and Koo, 2004) and attenuating inflammatory response to LPS in rats (El Alwani et al., 2006; Park et al., 2007). Milk polar lipids in the context of preexisting obesity may facilitate the understanding of the interrelationships among the intestinal barrier integrity, endotoxemia, systemic inflammation, lipid metabolism, and obesity.

High-fat-only models were used previously; this study is by far the first to explore milk polar lipids in preexisting obesity using C57BL/6J ob/ob (ob/ob) mice. The ob/ob mice have an inappropriate increase and distribution of TJ proteins and reduced gut barrier integrity (Ferraris and Vinnakota, 1995). The ob/ob mice under a standard chow diet have increased intestinal permeability and portal/plasma endotoxemia (Brun et al., 2007). We tested the hypotheses that dietary milk polar lipids, including PL and GG [at 1 and $0.02 \%$ by weight, respectively, similar to previous studies (Wat et al., 2009; Park et al., 2010)] will (1) reduce gut permeability, (2) reduce liver lipid accumulation, (3) affect hepatic expression of genes associated with fatty acid synthesis and cholesterol regulation, and (4) alleviate the systemic inflammation associated with obesity.

\section{MATERIALS AND METHODS}

\section{Diet Formulation}

The diets were based on the AIN-93G rodent diet and were further enriched with fat. Fat provided $34 \%$ of energy. This fat level is high compared with the $17.2 \%$ (energy) fat in the AIN-93G diet. Data from the National Health and Nutrition Examination Survey (2007-2008; Moshfegh et al., 2009) indicate that the mean amount of fat consumed per individual American was $34 \%$ by energy. Thus, using diets with $34 \%$ (energy) fat emulates the real dietary practices in America.

We formulated 3 diets (Table 1) so that they were identical in macro and micro nutrients except for the fat source, which were provided by soybean oil + lard (CO diet), soybean oil + lard + milk GG (GG diet), and soybean oil + lard + milk PL (PL diet), respectively. The milk polar lipids were provided as a semipurified milk PL concentrate or a semi-purified milk GG concentrate (Table 2) prepared from dried milk cream by ethanol extraction (Fonterra USA Inc., Rosemont, IL). The phospholipid content of the concentrate was analyzed by HPLC and P31 nuclear magnetic resonance. The ganglioside content of the concentrate was analyzed by HPLC. The GG was supplemented at 0.2 $\mathrm{g} / \mathrm{kg}$ of diet, including $0.17 \mathrm{~g}$ of ganglioside GD3 and $0.03 \mathrm{~g}$ of ganglioside GM3. The GG diet also contained a small amount of phosphatidylcholine, phosphatidylserine, phosphatidylethanolamine, and sphingomyelin $(0.55,0.48,0.21$, and $0.2 \mathrm{~g} / \mathrm{kg}$ of diet, respectively). Because the GG concentrate contained large amount of lactose, lactose was balanced in the other 2 diets. The PL was supplemented at $10 \mathrm{~g} / \mathrm{kg}$ of diet, including 2.9 $\mathrm{g}$ of sphingomyelin, $5 \mathrm{~g}$ of phosphatidylcholine, $1.6 \mathrm{~g}$ of phosphatidylethanolamine, and $0.6 \mathrm{~g}$ of phosphatidylserine. The choline contents of the diets were adjusted (Table 1 ) so that the 3 diets contained similar amounts of choline. The mineral contents of the diets were balanced (Table 1) and verified by the Utah Veterinary Diagnostic Laboratory. The fatty acid composition of the diets was analyzed by GC as described previously (Snow et al., 2010).

\section{Animals}

Five-week-old male ob/ob mice $(\mathrm{n}=18$; Jackson Laboratory, Sacramento, CA) were housed singly in cages at a constant temperature of $22 \pm 1^{\circ} \mathrm{C}$ with a 12-h light/dark cycle. The mice were allowed ad libitum access to diet and water. After 2 wk of feeding on chow (for acclimatization and baseline data collection), mice were randomly assigned to one of the following treatments: (1) CO diet $(\mathrm{n}=6),(2) \mathrm{GG} \operatorname{diet}(\mathrm{n}=6)$, and (3) PL diet $(\mathrm{n}=6)$. The mice were fed the experimental diets for 2 wk before being killed. Diet intake and BW were measured every other day. The body composition was assessed at baseline, $\mathrm{d} 4$, and d 13 by using magnetic resonance imaging (MRI) with an EchoMRI-900 Body Composition Analyzer (EchoMRI, Houston, TX). The experiments were conducted in conformity with the Public Health Service Policy on Humane Care and Use of Laboratory Animals and were approved by the Utah State University Institutional Animal Care and Use Committee (the protocol number was 1507). 
Table 1. Diet composition ${ }^{1}$

\begin{tabular}{lccc}
\hline Item & CO & GG & PL \\
\hline Ingredient (g/kg) & & & \\
Lard & 95.30 & 91.93 & 83.20 \\
Lactose & 6.87 & 0 & 5.88 \\
GG concentrate & 0 & 11.24 & 0 \\
PL concentrate & 0 & 0 & 14.24 \\
Water & 0.03 & 0.06 & 1.45 \\
Choline adjustment (g/kg) & & & \\
Choline bitartrate & 3.95 & 3.76 & 2.50 \\
Mineral adjustment (mg/kg) & & & \\
Sodium meta-silicate, nonahydrate & 7.7 & 0 & 1.5 \\
Sodium chloride & 196.8 & 20.5 & 0 \\
Potassium phosphate, monobasic & $1,259.7$ & 897.3 & 0 \\
Potassium sulfate & 281.4 & 0 & 644.7 \\
Calcium carbonate & 8 & 4.8 & 0 \\
Magnesium oxide & 1.1 & 0 & 0.1 \\
Energy contribution (kcal \%) & & & \\
Protein & 16.78 & 16.78 & 16.78 \\
Carbohydrate & 49.02 & 49.02 & 49.02 \\
Fat & 34.20 & 34.20 & 34.20 \\
Energy density (kcal/g) & 4.3 & 4.3 & 4.3 \\
\hline All diets containe 188 & & & \\
\hline
\end{tabular}

${ }^{1}$ All diets contained $188 \mathrm{~g} / \mathrm{kg}$ of vitamin-free casein, $3 \mathrm{~g} / \mathrm{kg}$ of L-cystine, $348 \mathrm{~g} / \mathrm{kg}$ of corn starch, $100 \mathrm{~g} / \mathrm{kg}$ of maltodextrin, $100 \mathrm{~g} / \mathrm{kg}$ of sucrose, $34.9 \mathrm{~g} / \mathrm{kg}$ of cellulose, $73 \mathrm{~g} / \mathrm{kg}$ of soybean oil, $35 \mathrm{~g} / \mathrm{kg}$ of AIN-93G mineral mix (Harlan Laboratories Inc., Madison, WI), $10 \mathrm{~g} /$ $\mathrm{kg}$ of AIN-93 vitamin mix, $0.15 \mathrm{~g} / \mathrm{kg}$ of food color, and $0.04 \mathrm{~g} / \mathrm{kg}$ of antioxidant tert-butylhydroquinone. $\mathrm{CO}$ group $=$ mice were fed the control diet; GG group = mice were fed the diet supplemented with milk gangliosides concentrate; PL group = mice were fed the diet supplemented with milk phospholipids concentrate.

\section{Assessments of Intestinal Barrier Integrity}

To assess intestinal permeability to macromolecules, 4,000 Da fluorescein isothiocyanate (FITC)-dextran (Sigma-Aldrich Co. LLC, St. Louis, MO) suspended in PBS was gavaged, and blood samples were collected through cheek bleeding $5 \mathrm{~h}$ after the gavage. Plasma concentrations of FITC-dextran were determined by measuring fluorescence at $530 \mathrm{~nm}$ (Peterson et al., 2010). Gut permeability was also assessed by using the differential sugar absorption test (DST; Meddings and

Table 2. Phospholipids (PL) and gangliosides (GG) concentrate composition $(\mathrm{g} / 100 \mathrm{~g})^{1}$

\begin{tabular}{lcc}
\hline Item & PL concentrate & GG concentrate \\
\hline Total lipids & 85 & 30 \\
Moisture & 2.5 & 3.5 \\
Ash & 6 & 8.3 \\
Lactose & 6.6 & 58 \\
Ganglioside GM3 & - & 0.3 \\
Ganglioside GD3 & 3 & 1.4 \\
Phosphatidylserine & 31 & 4.5 \\
Phosphatidylcholine & 8.7 & 5.1 \\
Phosphatidylethanolamine & 16.5 & 2 \\
Sphingomyelin & 1.7 \\
\hline
\end{tabular}

${ }^{1}$ GG group $=$ mice were fed the diet supplemented with milk gangliosides concentrate; PL group = mice were fed the diet supplemented with milk phospholipids concentrate.
Gibbons, 1998) to assess the permeability for different parts of the gastrointestinal tract. The DST was carried out according to the method of Arrieta et al. (2009). After a 4-h fast of food and water, the mice were gavaged with a sugar probe solution containing sucrose, lactulose, mannitol, and sucralose. Immediately after the gavage the mice were housed in metabolic cages to collect the 24-h urine. During the collection period, urine samples were preserved by addition to collection vessels of $5 \mathrm{mg}$ of sodium fluoride. The urinary sugars were quantified by the Farhadi method using GC (Farhadi et al., 2006).

\section{Tissue Sample Collection}

The mice were killed by $\mathrm{CO}_{2}$ asphyxiation after a 4-h fast. After blood collection, liver, quadriceps muscle, intestinal and colonic mucosa, feces, and adipose tissue samples were collected. The adipose depots, collected separately, included gonadal, retroperitoneal, mesenteric, and subcutaneous fat. Each category of tissue was saved separately and the tissue mass was recorded. The tissue samples were flash frozen and stored at $-80^{\circ} \mathrm{C}$ until further analysis.

\section{Biochemical Analyses of Plasma}

The blood was obtained by cheek bleeding and collected in heparin-containing tubes (BD, Franklin Lakes, NJ). Plasma samples were obtained after centrifugation at $12,000 \times g$ for $10 \mathrm{~min}$ and stored at $-80^{\circ} \mathrm{C}$. Plasma insulin, leptin, resistin, monocyte chemotactic protein-1 (MCP-1), IL-6, TNF- $\alpha$, and plasminogen activator inhibitor-1 (PAI-1) were determined by using the Milliplex mouse adipokine kit (Millipore, Billerica, MA). Plasma glucose was measured by using the Cholestech L.D.X system (Cholestech Corp., Hayward, CA). The homeostasis model assessment-estimated insulin resistance (HOMA-IR) index was calculated from the fasting glucose and insulin (fasting glucose $\times$ fasting insulin/22.5; Wallace et al., 2004). Plasma endotoxin was measured by the fluorescence endotoxin assays kit (Lonza Inc., Allendale, NJ).

\section{Western Immunoblotting for Zonula Occludens-1 and Occludin Proteins}

The small intestine (without the duodenum) and the colon were excised after the mouse was killed. The proximal one-third segment of the small intestine (jejunum), the distal two-thirds segment of the small intestine (ileum), and the entire length of the colon were collected and opened longitudinally. The intestine was washed with ice-cold $0.9 \%$ saline solution and the 
moisture was removed with tissue paper. The intestine segments were scraped with a glass slide to obtain the mucosa, which were flash frozen and stored at $-80^{\circ} \mathrm{C}$ until further analysis. Mucosal samples were homogenized in $500 \mu \mathrm{L}$ of ice-cold tissue protein extraction reagent (contains a proprietary detergent in $25 \mathrm{~m} M$ bicine, 150 $\mathrm{m} M$ sodium chloride; $\mathrm{pH} 7.6$ ) with $1 \%$ protease inhibitor and $1 \%$ phosphatase inhibitor (Pierce Biotechnology, Rockford, IL). The homogenates were centrifuged at $10,000 \times g$ for $5 \mathrm{~min}$ at $4^{\circ} \mathrm{C}$ to collect the supernatants. The protein samples were suspended in SDS sample buffer (Invitrogen, Grand Island, NY) and were boiled at $100^{\circ} \mathrm{C}$ for $5 \mathrm{~min}$. The proteins were separated by SDS-PAGE using $6 \%$ (ZO-1) or $8 \%$ to $16 \%$ (occludin, $\beta$-actin) Tris-glycine polyacrylamide gradient gels and subsequently transferred to nitrocellulose membranes (Invitrogen). The membranes were blocked with 5\% BSA in Tris-buffered saline $(0.0242 \%$ Tris base, $0.08 \%$ $\mathrm{NaCl} ; \mathrm{pH} 7.6) / 0.1 \%$ Tween 20 for $1 \mathrm{~h}$. The primary antibodies specific for ZO-1 (1:500; Zymed, Grand Island, NY), occludin (1:500; Santa Cruz Biotechnology, Santa Cruz, CA), or $\beta$-actin (1:500; Cell Signaling, Danvers, MA) were incubated with the membranes overnight at $4^{\circ} \mathrm{C}$ in $5 \%$ BSA with Tris-buffered saline/Tween 20. The membranes were washed and incubated for $1 \mathrm{~h}$ at room temperature with the secondary antibody horseradish peroxidase-linked antirabbit IgG (1:2,000; Cell Signaling) prepared in the blocking solution. After thorough washing, the Pierce Supersignal West Pico Chemiluminescent Kit was applied for antibody detection with Kodak 2000R Image Station (Raytest USA Inc., Wilmington, NC). The mean pixel density was estimated using ImageJ (National Institutes of Health, Bethesda, MD). The data were expressed as relative band density from the Western blots. The relative band density was calculated by dividing the pixel density of the target protein by the mean pixel density of $\beta$-actin.

\section{Liver Gene Expression Analysis}

The expression of genes associated with lipid metabolism in the liver was analyzed by real-time quantitative PCR (RT-qPCR) assays. The total RNA was extracted from the liver tissue by using the TRI reagent (Sigma-Aldrich Co. LLC) and the SurePrep RNA Purification Kit (Thermo Fisher Scientific Inc., Waltham, MA) according to the manufacturer's instructions. The genomic DNA in the RNA samples was eliminated with the RNase-free DNase I solution. The RNA $(1 \mu \mathrm{g})$ was reverse transcribed into the cDNA using the QuantiTect Reverse Transcription Kit (Qiagen, Valencia, CA) and MJ Mini Thermal Cycler (Bio-Rad, Hercules, CA). The real-time quantitative PCR was then performed with the EvaGreen method using the Biomark 48.48 Dynamic Arrays (Fluidigm, South San Francisco, CA). Primer sequences were as in Table 3. These mouse primers were selected from the Primer Bank developed by the Massachusetts General Hospital and Harvard Medical School (Wang et al., 2012). The cycle threshold $(\mathbf{C t})$ values for the genes of interest were normalized with the $\mathrm{Ct}$ values for peptidylprolyl isomerase A. The relative gene expression was calculated by using the $2^{-\Delta \Delta \mathrm{Ct}}$ method.

\section{Tissue Lipid Profiling}

Total lipids were extracted from $50 \mathrm{mg}$ (20 mg for the intestinal mucosa) of each tissue sample by the method of Folch et al. (1957) with slight modifications (Zhou et al., 2012). The individual lipid classes of the extracted lipid were separated using high-performance thin layer chromatography (HPTLC). The HPTLC plate $(10 \times 20 \mathrm{~cm}$ silica gel, $3 \mu \mathrm{m}$ particle, $100 \mu \mathrm{m}$ layer; Scientific Adsorbents Inc., Atlanta, GA) was pre-washed with $100 \mathrm{~mL}$ of chloroform/methanol (1:1 $\mathrm{vol} / \mathrm{vol}$ ) and activated in the $100^{\circ} \mathrm{C}$ oven for $10 \mathrm{~min}$. The lipid class standards were spotted for detecting the target bands. The aliquots of 5 - $\mu \mathrm{L}$ lipid sample (containing $2.5 \mathrm{mg}$ of the lipids) or plasma sample were spotted $1 \mathrm{~cm}$ from the bottom of the plate and the plate was air-dried. The plate development was carried out by the method of Kupke and Zeugner (1978). Briefly, the plate was developed twice in solvent system I (chloroform-methanol-water, 65:30:5) and then once in solvent system II (n-hexane-diethyl ether-acetic acid, $0.80: 20: 1.5)$. After being dried, the plate was sprayed until translucent with a $10 \%$ (wt/vol) cupric sulfate solution in $8 \%(\mathrm{wt} / \mathrm{vol}$ ) orthophosphoric acid (Baron and Coburn, 1984). The plate was heated in an oven at $145^{\circ} \mathrm{C}$ for $10 \mathrm{~min}$ (Churchward et al., 2008). The plate was scanned with a document scanner Epson Stylus NX400 (Epson America Inc., Long Beach, CA) and the lipid bands were quantified with ImageJ. The detected lipid classes from the HPTLC plate were phosphatidylethanolamine, phosphatidylcholine, phosphatidylserine, and phosphatidylinositol (PI), sphingomyelin, diacylglycerols, free fatty acids (FFA), triacylglycerols, and cholesteryl esters $(\mathbf{C E})$. The external standards for polar lipids and their sources were as the following: phosphatidylethanolamine (egg, chicken), phosphatidylcholine (egg, chicken), phosphatidylserine (brain, porcine), PI (liver, bovine), and sphingomyelin (egg, chicken). All external standards were purchased from Avanti Polar Lipids Inc. (Alabaster, AL). An internal standard, phenyl $N$-acetyl- $\alpha$-D-glucosaminide, was purchased from TCI America (Portland, OR). 


\section{Ganglioside Analysis of Intestinal Mucosa}

The total ganglioside content in the intestinal mucosa was determined by measuring the GG bound sialic acid with GC-MS. The GG were extracted and purified by using the Sep-Pak C18 reverse-phase cartridges (Waters, Milford, MA) according to the method of Schnabl et al. (2009). The GG were derivatized by trimethylsilylation. One hundred-microliter ganglioside samples with $5 \mu \mathrm{g}$ of phenyl $N$-acetyl- $\alpha$-D-glucosaminide as internal standard were dried and treated with $700 \mu \mathrm{L}$ of $0.05 \mathrm{~N}$ fresh methanolic $\mathrm{HCl}$ by heating for $1 \mathrm{~h}$ at $80^{\circ} \mathrm{C}$. The mixture was cooled and extracted with $0.5 \mathrm{~mL}$ of hexane to remove the liberated fatty acid esters. The methanolic layer was dried under a nitrogen stream. The trimethylsilylation derivatization reagent was formed according to the method of Carter and Gaver (1967). The silylation reagent $(50 \mu \mathrm{L})$ was added to the samples in the small ample vials. The samples were vortexed and allowed to stand for $15 \mathrm{~min}$. The deriva- tized samples were transferred into GC inserts and 1 $\mu \mathrm{L}$ was injected per assay into a DB-5 GC Column (Agilent, Santa Clara, CA) installed on a Shimadzu GC (Shimadzu, Colombia, MD) coupled with a MS. The quantification was achieved from the standard curve generated by concurrent analysis of a series of ganglioside GD3 standards in different concentrations.

\section{Statistical Analyses}

The statistical analyses were carried out by using software package SAS 9.2 (SAS Institute Inc., Cary, NC). For one-time measurements, 1-way ANOVA was performed and the group means were compared by the Ryan-Einot-Gabriel-Welsch multiple range test. For repeated measurements, mixed model ANOVA was performed to assess diet, time, and diet $\times$ time effect, and the group means were compared by the least squares means contrast. The data were reported as mean \pm standard error of the mean.

Table 3. Mouse primer sequences for real-time quantitative PCR assays

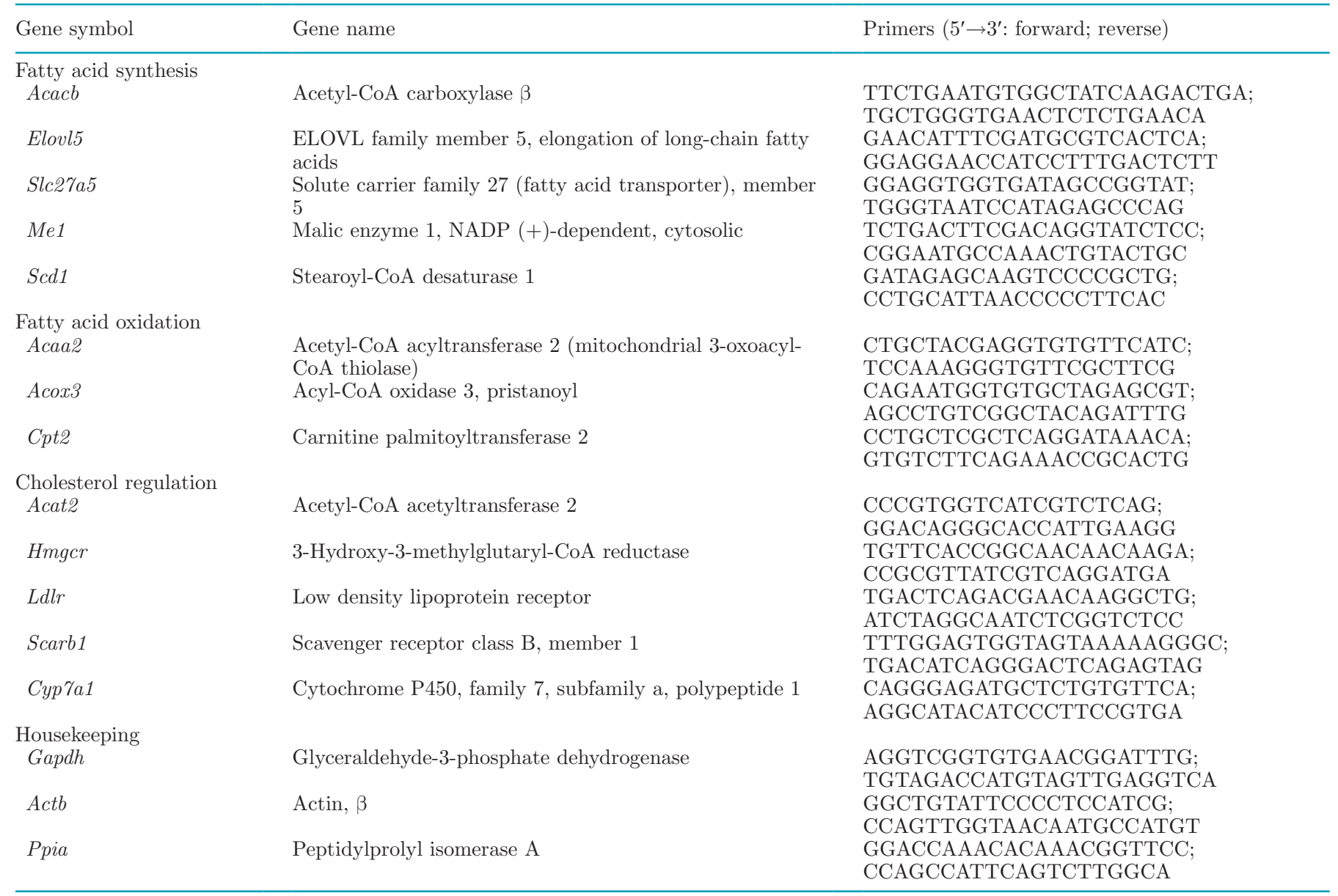




\section{RESULTS AND DISCUSSION}

\section{Animal Mortality}

One mouse each in the $\mathrm{CO}$ and GG group died during the MRI scan. After staying in the metabolic cage for $24 \mathrm{~h}$ for the final DST, 2 mice in the CO group, 1 mouse in the GG group, and 1 mouse in the PL group died. These deceased mice consumed less food compared with those that survived $(0.34 \pm 0.12 \mathrm{~g}$ vs. $1.83 \pm 0.62 \mathrm{~g}$ ) in the metabolic cage. One mouse in the PL group was killed after the final DST due to development of obvious diabetic symptoms. We killed the remaining mice $3 \mathrm{~d}$ after the final DST. Postmortem pathological examination of the dead mice by the Utah Veterinary Diagnostic Laboratory revealed no evidence of infectious disease in any tissues or organs. Hepatic lipidosis was severe and considered the primary cause of mortality.

Before putting the mice on the experimental diets, we fed them the chow diet and carried out a baseline DST. None of the mice had any abnormal symptoms after the baseline DST. At that time, they were small enough to easily access the food in the metabolic cage. After $2 \mathrm{wk}$, their increased size made it difficult to access the food in the metabolic cages and the dietary intake was reduced significantly $(5.9 \pm 0.5$ vs. $1.4 \pm 0.5$ g, $P<0.0001)$. Mice that died thereafter consumed less food in the metabolic cages and did not resume normal food consumption after they were returned to the regular cages. Nonalcoholic steatohepatitis develops in the ob/ob mice on a moderately high-fat diet $(35.7 \%$ by energy) for $4 \mathrm{wk}$ (de Lima et al., 2007). The ob/ob mice develop spontaneous liver steatosis, and a second metabolic "hit" may induce a more severe injury (Stefano et al., 2007). Starving for $24 \mathrm{~h}$ induces hepatic steatosis (Xu et al., 2012) in ob/ob mice. The food restriction in the present study was unintentional and it should have worsened the hepatic lipidosis. Extreme steatosis and stress in the metabolic cages may have resulted in the animal mortality. For the final tissue analyses, the mice killed at the end were used [CO $(\mathrm{n}=3), \mathrm{GG}(\mathrm{n}=4)$, and PL $(\mathrm{n}=4)]$. Although the number of animals per group became small after animal mortality, the data on gut permeability were collected before the animal deaths.

\section{Food Intake, Weight Gain, and Tissue Mass}

Dietary polar lipid supplementation did not affect the daily food intake and weight gain. No significant differences were observed in the tissue masses of total, subcutaneous, and visceral adipose depots. The PL and GG groups had less mesenteric fat as a percentage of
BW compared with the CO group $(2.64 \pm 0.37$ and 2.60 \pm 0.15 vs. $3.58 \pm 0.41 \mathrm{~g}$, GG vs. CO: $P=0.05$, PL vs. CO: $P=0.06)$. Accumulation of mesenteric fat around the bowel may contribute to inflammation by synthesis of TNF- $\alpha$ and may be involved in the pathogenesis of Crohn's disease (Karagiannides and Pothoulakis, 2008). Therefore, dietary GG and PL may pose some benefits regarding intestinal inflammation. As a portion of BW, the fat percentage increased in all groups as a function of time (Figure 1a). There was a trend (diet effect, $P=$ 0.29 ) that mice in the PL group accumulated fat at a faster rate. The area under the curve for the PL group was greater than that of the GG and CO groups (Figure 1a). Dietary polar lipids, especially the PL, lowered the overall liver mass and liver mass normalized to BW (diet effect, $P=0.02$, Figure $1 \mathrm{~b}$ ). This observation is consistent with previous findings although the relevant mechanisms remain to be elucidated (Wat et al., 2009). Given the fact that total body fat may have increased in the PL group, further studies are needed to determine whether the effect of PL on liver mass is beneficial or not. It could be possible that there was redistribution of fat in the body. If PL just changed fat distribution between liver and peripheral tissues, this effect of PL could be beneficial because fatty liver can be deadly and therefore may have a more direct and significant effect on overall health. The biological and molecular mechanisms for this phenomenon could become clearer if further detailed studies are carried out. For example, total body fat measurement was not done for most of the previous studies.

\section{Tissue Lipid Profiles and Gene Expression}

The following lipid classes were analyzed in the liver, skeletal muscle, gonadal fat depot, and intestinal mucosa: phosphatidylethanolamine, phosphatidylcholine, phosphatidylserine, and PI, sphingomyelin, diacylglycerols, FFA, triacylglycerols, and CE. There was no significant treatment effect for most of the lipid classes in the tissues (data not shown). Dietary polar lipids, especially the PL, decreased CE and PI in the liver and decreased PI in the skeletal muscle $(P<0.05$, Figure 1c) but did not affect other lipid classes in these tissues. The decrease of the hepatic CE may have partially resulted from the reduction of the intestinal cholesterol uptake by the PL (Kamili et al., 2010). Dietary polar lipids did not affect the lipid profiles of intestinal mucosa and gonadal fat depot.

Compared with the CO, the GG and the PL downregulated hepatic expression of the fatty acid oxidation gene Acaa2 and the fatty acid synthesis gene Acacb ( $P$ $<0.05$, Figure 1d). The PL upregulated the hepatic expression of the cholesterol esterifying gene Acat2 ( $P$ 
a

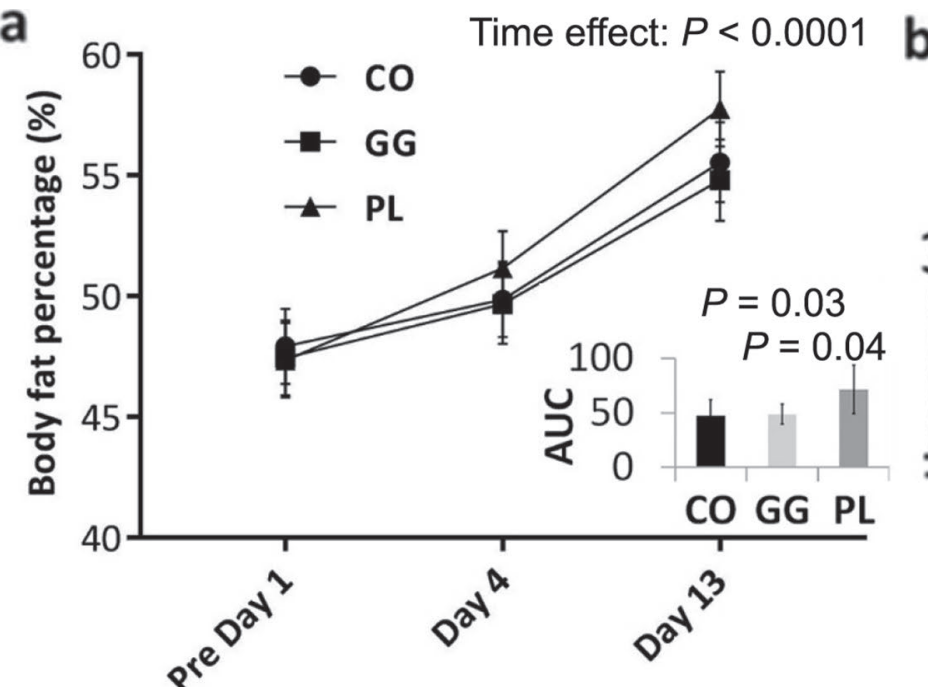

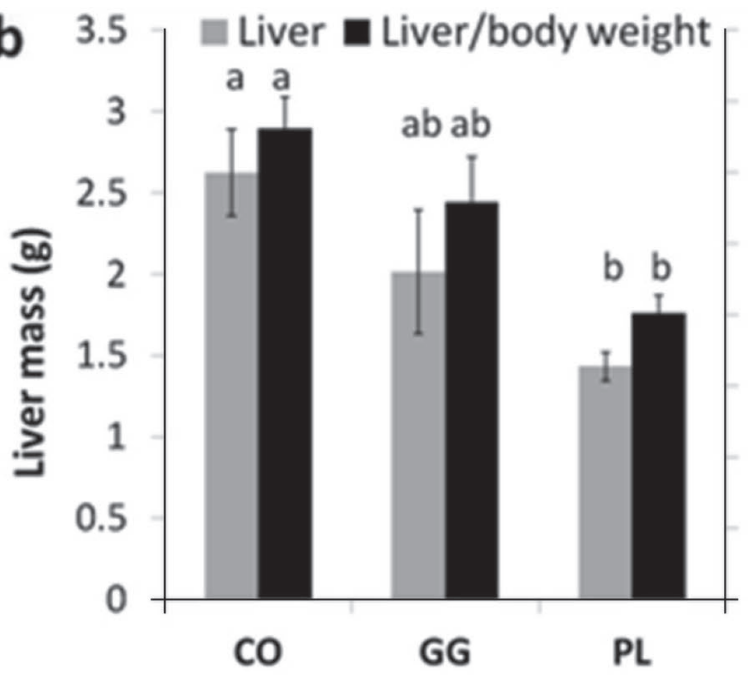
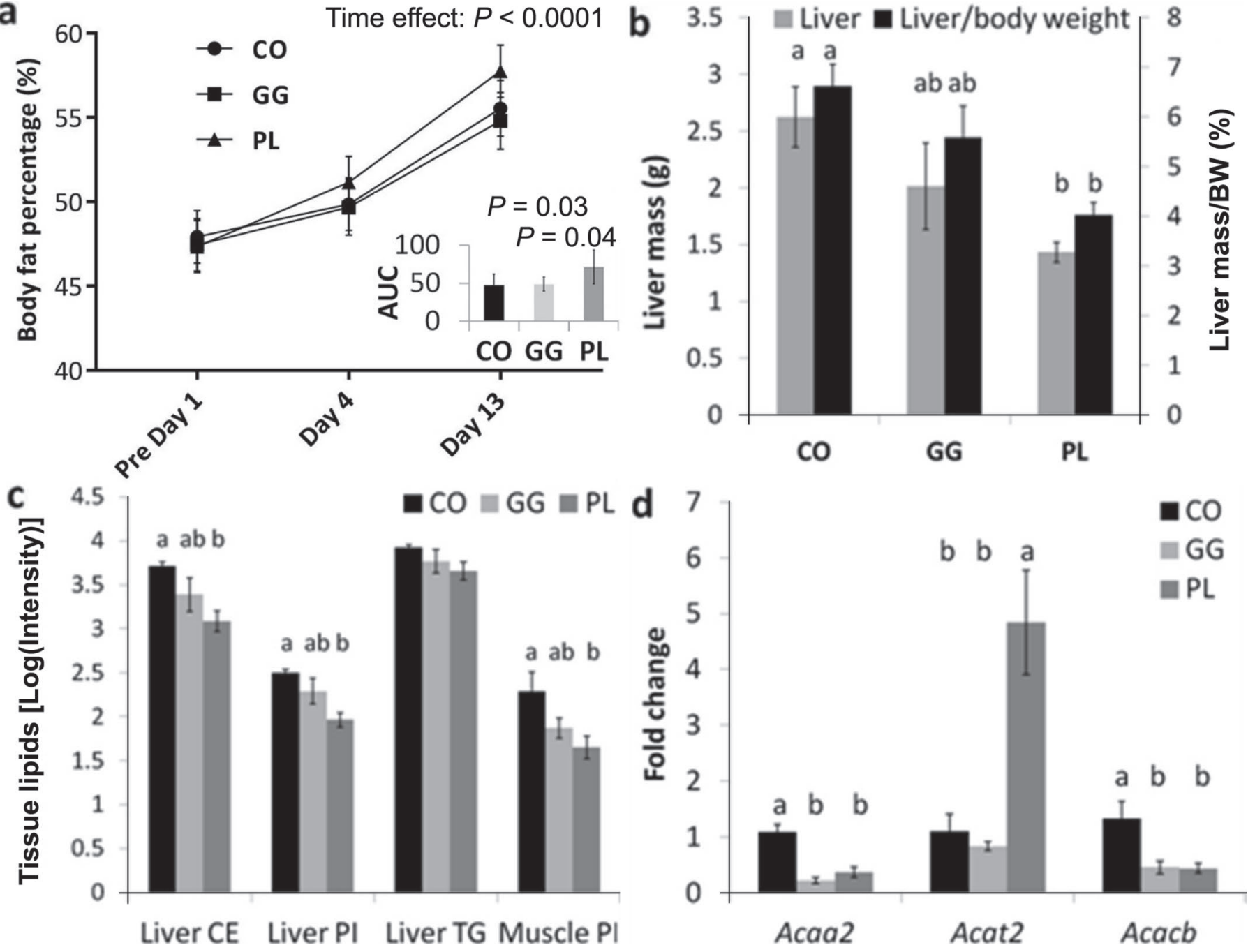

Figure 1. Effects of milk polar lipids on (a) body fat (values are LSM \pm SEM, $\mathrm{n}=6$ at pre $\mathrm{d} 1 ; \mathrm{n}=6,5$, and 6 at $\mathrm{d} 4 ; \mathrm{n}=5,5$, and 6 at d 13 for CO, GG, and PL, respectively), (b) liver mass ( $\mathrm{CE}=$ cholesteryl esters; PI = phosphatidylinositol; TG = triacylglycerols), (c) tissue lipids, and $(\mathrm{d})$ hepatic gene expression. The data represent mean \pm SEM $(\mathrm{n}=3,4$, and 4 for $\mathrm{CO}$, GG, and PL, respectively). Means in a group with different letters are different based on Ryan-Einot-Gabriel-Welsch multiple range test, $P<0.05$. CO group $=$ mice were fed the control diet; GG group = mice were fed the diet supplemented with milk gangliosides concentrate; PL group = mice were fed the diet supplemented with milk phospholipids concentrate. AUC = area under the curve.

$<0.05$, Figure 1d), the enzyme responsible for synthesis of the CE (Wrenn et al., 1995). Soybean lecithin and phosphatidylcholine downregulate the expression of Acat2 in the liver (LeBlanc et al., 2003). Different sources of PL may have different effects on the Acat2 expression in the liver. Surprisingly the increase of Acat2 expression was accompanied by the decrease of $\mathrm{CE}$ in the liver and plasma. A high-cholesterol and high-fat diet usually upregulates hepatic ACAT activity and expression (Kushwaha et al., 2005). It may be hypothesized that the inhibition of cholesterol uptake by the PL overpowered its effect on Acat2 expression. Another dietary source of milk PL, at 1.25\% (similar to $1 \%$ in the current study) by weight, did not affect
Acaa and Acat2 and downregulated several fatty acid synthesis genes in the C57BL/6 mice on a high-fat diet and downregulated genes for cholesterol regulation in the context of a low-fat diet (Wat et al., 2009). The Acat2 expression was not affected by PL in the study by Wat et al. (2009), which may be due to the difference in dietary fat level. The Acat2 expression was somehow upregulated by PL in the context of a low-fat diet in the study by Wat et al. (2009). The beneficial effect of milk polar lipids on hepatosteatosis and lipidemia reported by Wat et al. (2009) may result from, at least partially, the PI, which has an antiobesity effect through regulating gene expression associated with hepatic lipid metabolism in a mouse model of diet-induced 
obesity (Shimizu et al., 2010). Those beneficial effects of polar lipids could also be partially due to the choline contributed by the phosphatidylcholine when the mice were fed high sucrose-hepatosteatosis-promoting diets (Bacon et al., 1984). The milk polar lipids concentrates used in the present study did not contain significant amount of PI and the amount of choline was balanced among diets (Table 1). The differences in animal model and the composition of PL may explain the disparity in the findings between the present study and the Wat et al. (2009) study.

The following genes associated with lipid metabolism in the liver were not affected by the treatments: fatty acid synthesis: Elovl5, Slc27a5, Me1, and Scd1; fatty acid oxidation: Acox3 and Cpt2; and cholesterol regulation: Hmgcr, Ldlr, Scarb1, and Cyp7a1. The PL group had higher plasma FFA (Figure 2a) and diacylglycerols (Figure 2b) compared with the GG and CO groups. The PL group had higher plasma sphingomyelin (Figure 2c) and total PL (Figure 2d) compared with the GG and CO groups. There was a trend (diet effect: $P=$ $0.15)$ that the PL may have increased plasma TG compared with the GG and CO (Figure 2e). Plasma CE did not change significantly over time and was not affected the treatments (Figure 2f). The observed differences in plasma sphingomyelin and total PL may be directly related to the differences in phospholipid intake. There was a possible contribution of TG-rich lipoproteins (intestinally and liver-derived) to the increase of other plasma lipids with milk polar lipids diets, especially for the PL diet. Further studies are needed to clarify this.

The data from the current study supported the hypotheses that dietary PL will reduce liver lipid accumulation and affect hepatic expression of genes associated with fatty acid synthesis and cholesterol regulation. However, those hypotheses were not supported for dietary GG. Dietary GG and PL were associated with decreased hepatic lipids and increased lipid in plasma. It is not clear whether this partitioning of fats is beneficial or not. Further studies are needed to explore the potential mechanisms and implications.

\section{Gut Permeability}

Plasma FITC-dextran decreased significantly during the feeding period (Figure 3a), which is an indication that the permeability of the small intestine decreased since FITC-dextran should be mainly absorbed in the small intestine (Yamaki et al., 2013). The polar lipids did not affect plasma FITC-dextran or the concentration of plasma LPS. The decrease of gut permeability to large molecules may be due to the gut maturation during development when the mice were 7 to $9 \mathrm{wk}$ old (Flurkey et al., 2007).
No change was observed in the urinary ratios of lactulose/mannitol, sucrose/lactulose, or lactulose/sucralose, but the urinary sucralose/mannitol ratio increased (Figure 3b). There was no significant dietary treatment effect on the urinary sugar ratios. Plasma LPS was increased by 3 - to 4 -fold during the study (Figure 3c). The rise of urinary sucralose/mannitol ratio without the lactulose/mannitol ratio being affected indicated that the permeability of the colon increased (Meddings and Gibbons, 1998). This may explain the increase of plasma LPS through enhanced LPS absorption from the colon. The possibility of increased LPS absorption by chylomicrons cannot be ruled out (Moreira et al., 2012). Compromised ileal mucosal integrity contributes to metabolic endotoxemia in rats fed high-fat diets (Guerville et al., 2017). Increased jejunal permeability correlates with systemic and intestinal inflammation in humans with severe obesity (Genser et al., 2018). Results from the current study indicate that a moderate fat diet may significantly increase plasma LPS by increasing the permeability of the colon in the context of preexisting obesity. Chylomicronemia due to increase of fat intake raises postprandial endotoxemia in obese men but not men with normal weight. Enrichment of chylomicrons with LPS and LPS binding protein together is the driving force for the acute inflammatory response (Vors et al., 2015). The implication of this observation could be of guiding significance to management of obesity.

The PL and the GG decreased ZO-1 protein in the jejunum mucosa compared with the CO (Figure $3 \mathrm{~d}$ ). The TJ protein ZO-1 was not affected in the mucosa of the ileum and colon (Figure 3d). The GG slightly increased occludin protein in the colon mucosa compared with the PL and CO (Figure 3d). The polar lipids did not affect occludin protein in the mucosa of the small intestine (Figure 3d). The increase of occludin was accompanied by an increase of colon permeability (Figure $3 \mathrm{~b}$ and d). Thus, changes in TJ protein content in intestinal mucosa do not necessarily result in change of gut permeability because the distribution of TJ proteins also plays an important role in affecting gut permeability (Ferraris and Vinnakota, 1995). The PL and GG groups had less phosphatidylcholine per gram of tissue in the mucosa of the small intestine although the diets had higher amounts of phosphatidylcholine compared with the $\mathrm{CO}$ group. There were no differences in other phospholipid classes in the intestinal mucosa among the groups. These data do not support the hypothesis that the dietary GG and PL may increase the intestinal barrier integrity through enriching the GG and PL in the intestinal mucosa. A recent mouse study indicates that milk polar lipids improve gut barrier integrity by increasing mucus-producing goblet cells (Lecomte et 

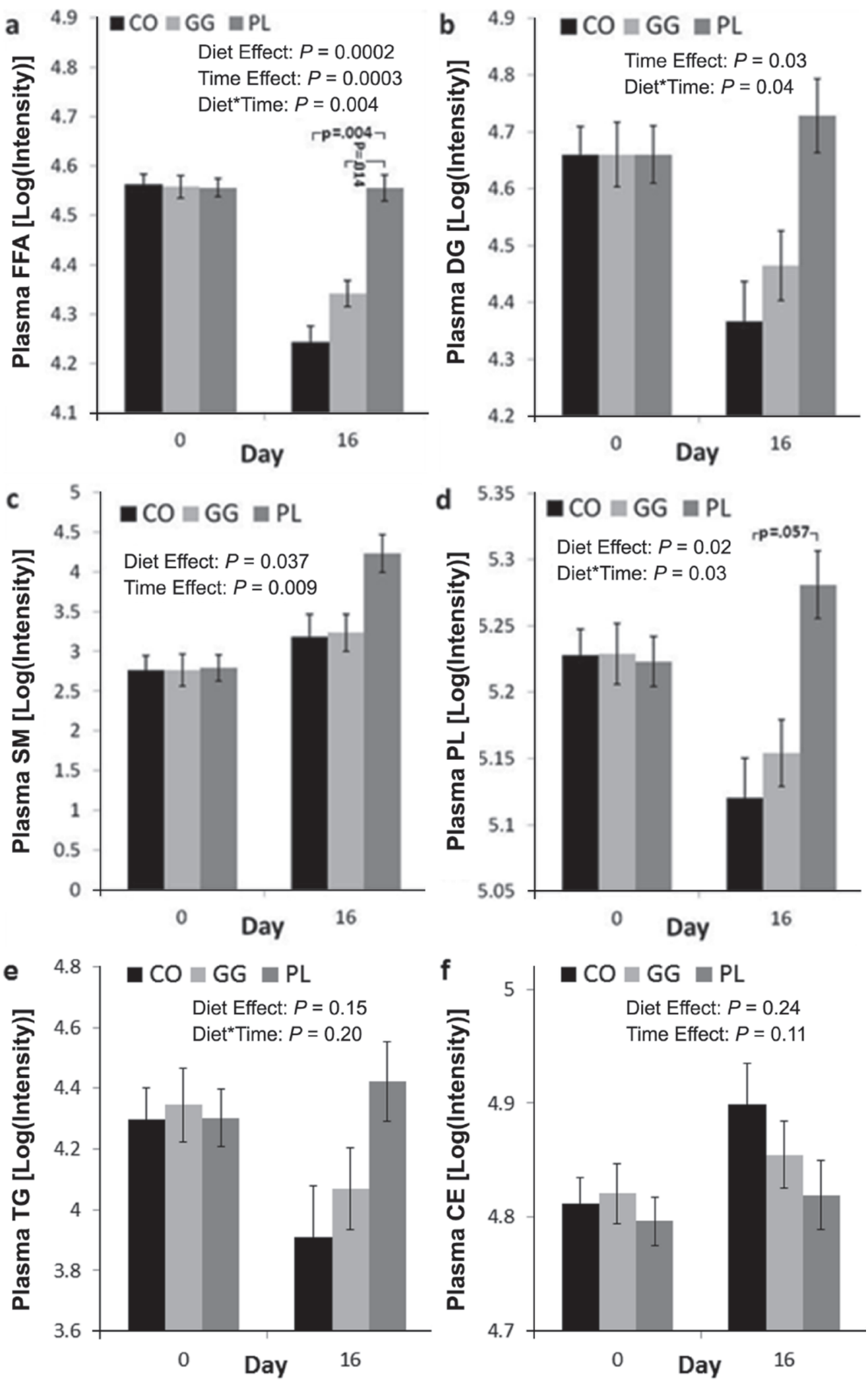

Figure 2. Effects of milk polar lipids on plasma lipid profile. The data represent LSM \pm SEM ( $=5$, 4, and 6 at d 0 for CO, GG, and PL; $\mathrm{n}=3,4$, and 3 at $\mathrm{d} 16$ for CO, GG, and PL, respectively). CO group = mice were fed the control diet; GG group = mice were fed the diet supplemented with milk gangliosides concentrate; PL group = mice were fed the diet supplemented with milk phospholipids concentrate. FFA $=$ free fatty acids; $\mathrm{DG}=$ diacylglycerols; $\mathrm{SM}=$ sphingomyelin; $\mathrm{PL}=$ phospholipids; $\mathrm{TG}=$ triacylglycerols; $\mathrm{CE}=$ cholesteryl esters . 
al., 2016). This effect was possibly due to the verylong-chain fatty acids specific to milk polar lipids. The expansion of colonic goblet cells is associated with a lower adiposity and inflammation in the context of high-fat diets. The findings in the present study was limited by the low number of animals. The observations should be confirmed using a larger number of animals and possibly using other models of gut barrier altera-
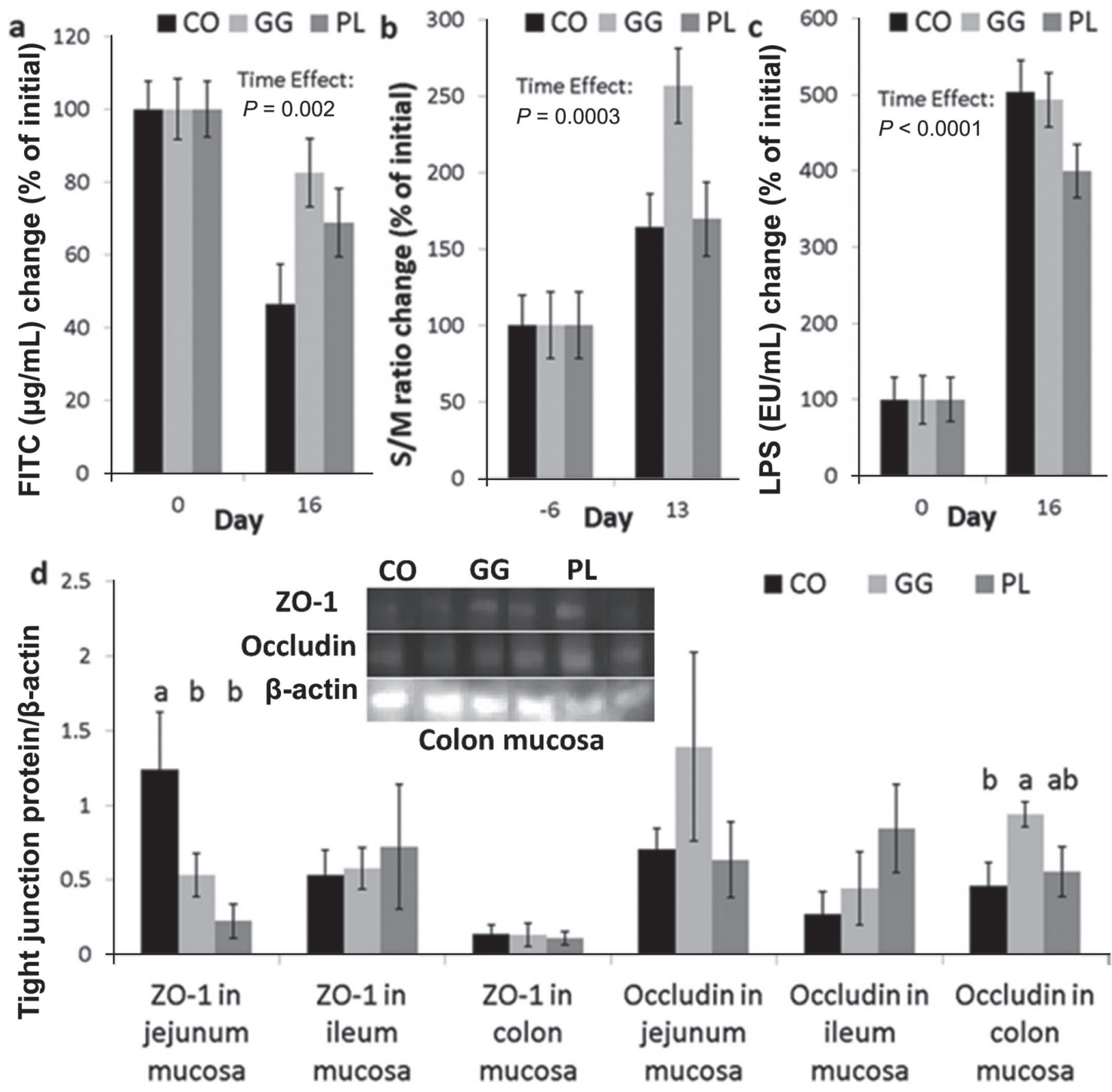

Figure 3. Effects of milk polar lipids on (a) plasma fluorescein isothiocyanate (FITC), (b) sucralose:mannitol ratio, (c) plasma LPS, and (d) tight junction protein expression in intestinal mucosa. The data represent LSM (a, b, c) or mean $(\mathrm{d}) \pm \mathrm{SEM}(\mathrm{n}=6,5$, and 6 at $\mathrm{d} 0$ and $\mathrm{n}=3$, 4 , and 4 at d 16 for panels a and $\mathrm{c} ; \mathrm{n}=6,5$, and 5 at d 0 and $\mathrm{n}=5,4$, and 4 at $\mathrm{d} 13$ for panel $\mathrm{b} ; \mathrm{n}=3$, 4 , and 4 for panel d, respectively, for the CO, GG, and PL groups). Means in a group with different letters are different based on Ryan-Einot-Gabriel-Welsch multiple range test, $P$ $<0.05$. CO group $=$ mice were fed the control diet; GG group $=$ mice were fed the diet supplemented with milk gangliosides concentrate; PL group $=$ mice were fed the diet supplemented with milk phospholipids concentrate. $\mathrm{ZO}-1$ = zonula occludens- 1 . 
tion (e.g., ulcerative colitis induced by high-fat diet and dextran sulfate sodium).

\section{Plasma Biochemistry and Systemic Inflammation}

The PL increased plasma IL-6 from 41 to $745 \mathrm{pg} /$ $\mathrm{mL}(P=0.001)$. Plasma IL-6 did not change in the CO group (18 vs. $16 \mathrm{pg} / \mathrm{mL}$ ). The GG increased plasma IL-6 from 44 to $133 \mathrm{pg} / \mathrm{mL}$. Plasma IL-6 in the PL group was significantly higher than that in the GG and CO groups (Figure 4a, $P=0.02$ and 0.01 , respectively). The correlation between plasma IL- 6 and plasma sphingomyelin was strong in the GG and PL groups (GG: $\mathrm{r}=0.97, P=0.03 ;$ PL: $\mathrm{r}=0.99, P=0.08)$ but not significant in the CO group $(\mathrm{r}=0.10, P=0.94$; Figure 4e). The correlation between plasma FFA and IL-6 was not significant in all groups (Figure 4f). Although SFA may increase plasma IL- 6 by activating the TLR 4 (Laugerette et al., 2012), no difference was observed in dietary fatty acids among groups (Table 4). Therefore, the increase of plasma IL- 6 should not have been due to SFA.

The correlation between plasma LPS and IL-6 was negative and statistically nonsignificant $(\mathrm{r}=-0.98, P$ $=0.14$ ) in the $\mathrm{CO}$ group, was negative and strong in the GG group $(\mathrm{r}=-0.97, P=0.02)$, but was not significant in the PL group $(\mathrm{r}=0.73, P=0.27)$. The effect of dietary sphingomyelin on plasma IL-6 has not been reported in mice. Nonfermented dairy consumption increases plasma sphingomyelin and IL-6 compared with the consumption of fermented dairy or low-fat dairy in overweight/obese subjects (Nestel et al., 2013). The increased plasma sphingomyelin could cause the increase of IL-6 through stimulating the adipocytes (Samad et al., 2006). Sphingomyelin is metabolized in the gut to generate ceramide, which is associated with inflammation (Duan and Nilsson, 2009). Although plasma LPS increased and LPS has the potential to activate the TLR4 and initiate inflammation, plasma IL-6 did not increase in the $\mathrm{CO}$ and GG groups in which the LPS increased similarly as in the PL group. The correlation between plasma LPS and IL-6 was negative in the CO and GG groups and not significant in the PL group. These results suggest that higher dietary sphingomyelin may have increased plasma sphingomyelin and IL-6 in the PL group compared with the other groups. Milk sphingomyelin at $0.25 \%$ by weight lowers endotoxemia (Norris et al., 2016) and at $0.1 \%$ by weight attenuates inflammation adipose tissue (Norris et al., 2017) in mice fed diets with very high level of fat (45 and $60 \%$ by energy, respectively). The PL diet of the current study contained similar amount of sphingomyelin ( $0.24 \%$ by weight). The effect of sphingomyelin may vary depending on the level of dietary fat. It could also be possible that the effect of sphingomyelin was interfered with by other components of milk polar lipids. One of the main concerns of the increased gut permeability is the resultant increase of the LPS absorption. The findings of this study suggest that plasma lipids may play more important roles in the inflammatory response than the gut permeability in the ob/ob mouse model. Dietary supplementation of the milk PL may pose negative effects by raising plasma sphingomyelin in the ob/ob mice.

Plasma TNF- $\alpha$ did not change significantly over time and were not significantly affected by dietary polar lipid supplementation (Table 5). Some of the TNF- $\alpha$ measurements were close or below the minimum detection limit, $10 \mathrm{pg} / \mathrm{mL}$. The effect of PL and GG on plasma TNF- $\alpha$ needs to be confirmed with further studies using more sensitive method. For example, modified floating electrode-based sensor can detect $\mathrm{TNF}-\alpha$ with a limit of $1 \mathrm{pg} / \mathrm{L}$ (Pham Ba et al., 2018). The current data suggest that dietary PL or GG may not alleviate the systemic inflammation associated with obesity in this model of severe obesity. The LPS binding protein and soluble cluster of differentiation 14 were suggested as better endotoxemia markers reflecting plasma exposure to LPS in humans (Laugerette et al., 2014). Milk polar lipids at $2 \%$ by weight significantly decreases plasma LPS binding protein in mice under a diet with $40 \%$ fat by energy (Lecomte et al., 2016). In the current study, we observed a significant increase of plasma LPS but a small change of IL-6 over time in the CO and GG groups. The LPS binding protein should be measured in future studies to more comprehensively assess the effect of endotoxemia.

Compared with baseline values, there was an increase of plasma PAI-1, resistin, and leptin. Plasma PAI-1 increased 2- to 5-fold (time effect, $P=0.0007$, Figure 4b). The final plasma PAI-1 level was similar to that in older (12 to 15 wk old) ob/ob mice fed a standard diet (Oishi et al., 2006) and was much lower than the level in 8 -wk-old ob/ob mice fed a diet with $35 \%$ fat by mass for $5 \mathrm{wk}$ (Alessi et al., 2003). The elevated plasma PAI1 level may be a result of complex interaction between hepatic accumulation of free fatty acids and innate immunity (Alessi et al., 2003). Dietary PL or GG affected plasma PAI-1.

Plasma resistin increased 1- to 2-fold (time effect, $P<0.0001$, Figure 4c). The final plasma resistin level was lower than that of 14-wk-old ob/ob mice fed a normal chow diet (Singhal et al., 2008). The GG increased plasma resistin compared with the $\mathrm{CO}$ and the PL (diet $\times$ time effect, $P=0.03$, Figure $4 \mathrm{c}$ ). Increased expression of resistin impairs insulin sensitivity and lipid metabolism (Singhal et al., 2008). The increase of plasma resistin by GG may result in unwanted effects. Plasma 

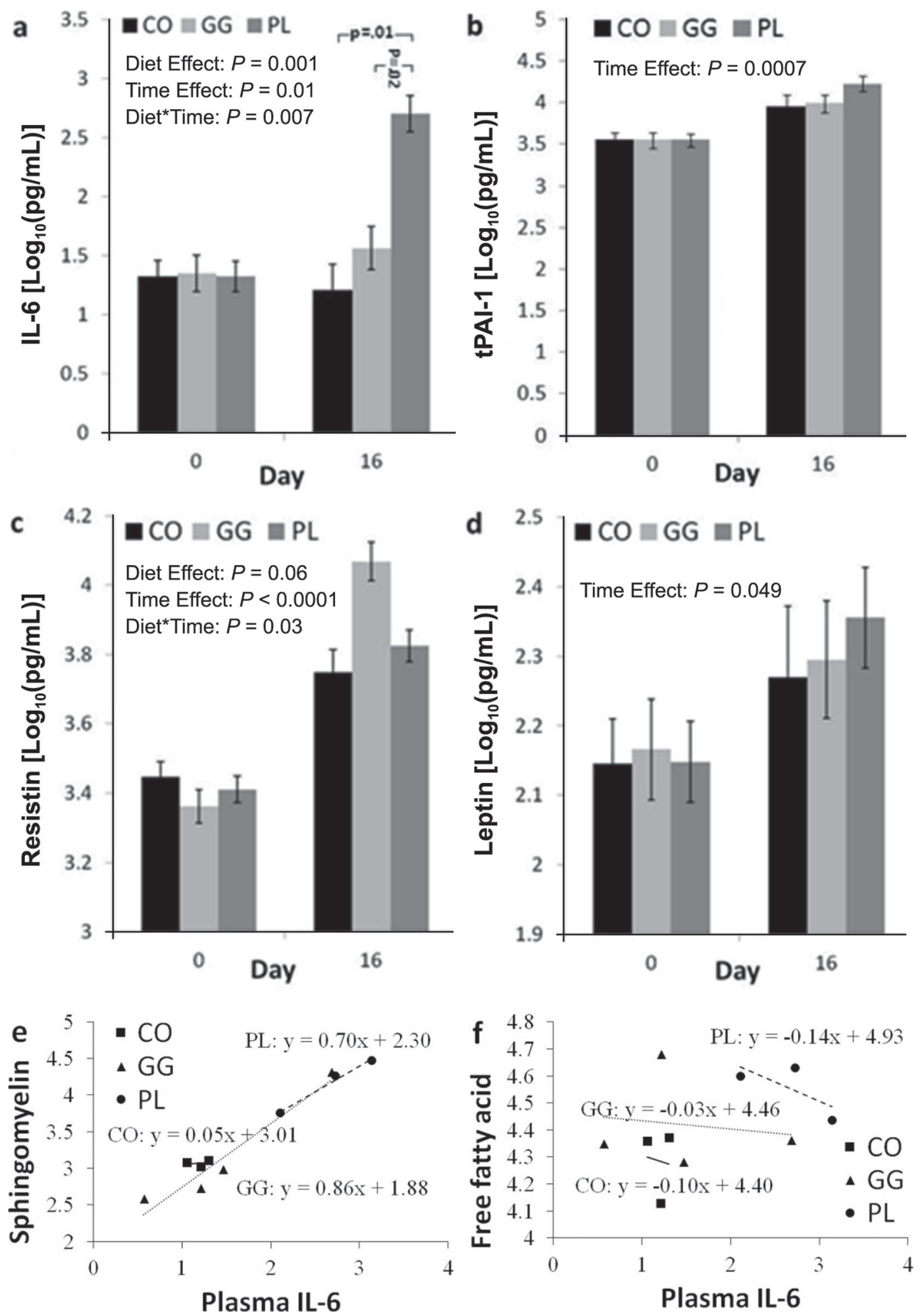

Figure 4. Effects of milk polar lipids on plasma cytokines (a) IL-6, (b) tissue plasminogen activator inhibitor-1 (tPAI-1), (c) resistin, and (d) leptin, and correlations between plasma IL-6 and sphingomyelin (e) or free fatty acid (f). The data represent LSM \pm SEM (n $=5,4$, and 6 at $\mathrm{d} 0$ and $\mathrm{n}=3,4$, and 4 at $\mathrm{d} 16$ for $\mathrm{CO}, \mathrm{GG}$, and PL, respectively). $\mathrm{CO}$ group = mice were fed the control diet; GG group $=$ mice were fed the diet supplemented with milk gangliosides concentrate; PL group = mice were fed the diet supplemented with milk phospholipids concentrate. 
Table 4. Fatty acid profile for diets $(\mathrm{mol} \%)^{1}$

\begin{tabular}{lrrr}
\hline Fatty acid & \multicolumn{1}{c}{ CO } & \multicolumn{1}{c}{ GG } & \multicolumn{1}{c}{ PL } \\
\hline C10:0 & $0.13 \pm 0.01$ & $0.15 \pm 0.00$ & $0.15 \pm 0.01$ \\
C12:0 & $0.13 \pm 0.01$ & $0.15 \pm 0.01$ & $0.19 \pm 0.01$ \\
C14:0 & $1.03 \pm 0.01$ & $1.07 \pm 0.00$ & $1.18 \pm 0.02$ \\
C15:0 & $0.10 \pm 0.01$ & $0.09 \pm 0.00$ & $0.11 \pm 0.01$ \\
C16:0 & $18.77 \pm 0.03$ & $18.62 \pm 0.03$ & $18.51 \pm 0.02$ \\
C16:1n-7 trans & $0.23 \pm 0.01$ & $0.23 \pm 0.01$ & $0.22 \pm 0.01$ \\
C16:1n-7 & $1.28 \pm 0.01$ & $1.28 \pm 0.01$ & $1.24 \pm 0.00$ \\
C17:0 & $0.28 \pm 0.01$ & $0.29 \pm 0.00$ & $0.30 \pm 0.01$ \\
C17:1n-7 & $0.25 \pm 0.01$ & $0.23 \pm 0.01$ & $0.25 \pm 0.00$ \\
C18:0 & $8.13 \pm 0.03$ & $8.20 \pm 0.01$ & $8.08 \pm 0.00$ \\
C18:1n-9 trans & $0.17 \pm 0.07$ & $0.31 \pm 0.02$ & $0.24 \pm 0.05$ \\
C18:1n-9 & $29.08 \pm 0.01$ & $29.00 \pm 0.04$ & $28.83 \pm 0.04$ \\
C18:1n-7 & $1.94 \pm 0.02$ & $1.92 \pm 0.01$ & $1.85 \pm 0.02$ \\
C18:2n-6 & $32.83 \pm 0.02$ & $32.77 \pm 0.01$ & $32.92 \pm 0.08$ \\
C18:3n-6 & $0.27 \pm 0.02$ & $0.28 \pm 0.02$ & $0.25 \pm 0.01$ \\
C18:3n-3 & $0.21 \pm 0.02$ & $0.21 \pm 0.02$ & $0.21 \pm 0.01$ \\
C20:1n-9 & $0.20 \pm 0.01$ & $0.20 \pm 0.00$ & $0.21 \pm 0.01$ \\
C20:0 & $3.22 \pm 0.02$ & $3.23 \pm 0.01$ & $3.35 \pm 0.02$ \\
C20:2n-6 & $0.48 \pm 0.01$ & $0.47 \pm 0.01$ & $0.44 \pm 0.01$ \\
C22:0 & $0.38 \pm 0.02$ & $0.38 \pm 0.01$ & $0.35 \pm 0.02$ \\
C20:3n-6 & $0.18 \pm 0.01$ & $0.17 \pm 0.00$ & $0.18 \pm 0.02$ \\
C20:4n-6 & $0.10 \pm 0.01$ & $0.09 \pm 0.01$ & $0.08 \pm 0.01$ \\
C22:1 & $0.10 \pm 0.05$ & $0.15 \pm 0.00$ & $0.17 \pm 0.01$ \\
C20:5n-3 & $0.11 \pm 0.00$ & $0.07 \pm 0.02$ & $0.08 \pm 0.01$ \\
\hline Val & &
\end{tabular}

${ }^{1}$ Values are mean \pm SEM of 3 replicates. CO group $=$ mice were fed the control diet; GG group = mice were fed the diet supplemented with milk gangliosides concentrate; PL group = mice were fed the diet supplemented with milk phospholipids concentrate.

leptin increased slightly (time effect, $P=0.049$, Figure 4d). The plasma leptin level in ob/ob mice has not been reported that we are aware of. The plasma leptin in ob/ob mice was not routinely measured probably due to the assumption that leptin is not present in the plasma of leptin-deficient ob/ob mouse. In the current study, the leptin level increased significantly from baseline to $16 \mathrm{~d}$. The serum leptin level is very low (close

Table 5. Effects of milk polar lipids on plasma monocyte chemotactic protein-1 (MCP-1), tumor necrosis factor- $\alpha$ (TNF- $\alpha)$, and insulin, glucose, and homeostasis model assessment of insulin resistance (HOMA-IR) in C57BL/6J ob/ob mice [units: $\log _{10}(\mathrm{pg} / \mathrm{mL})$ for cytokines; $\mathrm{m} M$ for glucose; arbitrary for HOMA-IR $]^{1}$

\begin{tabular}{lccc}
\hline Item & CO & GG & PL \\
\hline Baseline & & & \\
MCP-1 & $1.86 \pm 0.09$ & $1.66 \pm 0.14$ & $1.66 \pm 0.05$ \\
TNF- $\alpha$ & $1.43 \pm 0.03$ & $1.45 \pm 0.02$ & $1.33 \pm 0.06$ \\
Insulin & $3.62 \pm 0.09$ & $3.34 \pm 0.18$ & $3.57 \pm 0.08$ \\
Day 16 & & & \\
MCP-1 & $1.88 \pm 0.31$ & $2.09 \pm 0.22$ & $2.09 \pm 0.23$ \\
TNF- $\alpha$ & $1.40 \pm 0.04$ & $1.47 \pm 0.12$ & $1.53 \pm 0.21$ \\
Insulin & $3.50 \pm 0.03$ & $3.48 \pm 0.03$ & $3.57 \pm 0.07$ \\
Glucose & $15.04 \pm 1.01$ & $18.94 \pm 4.80$ & $14.97 \pm 7.01$ \\
HOMA-IR & $60.09 \pm 1.39$ & $76.54 \pm 23.37$ & $67.82 \pm 48.02$ \\
\hline
\end{tabular}

${ }^{1}$ Values are mean \pm SEM $(\mathrm{n}=5,4$, and 6 at $\mathrm{d} 0$ and $\mathrm{n}=3,4$, and 4 at d 16 for $\mathrm{CO}, \mathrm{GG}$, and $\mathrm{PL}$, respectively). $\mathrm{CO}$ group $=$ mice were fed the control diet; GG group = mice were fed the diet supplemented with milk gangliosides concentrate; PL group = mice were fed the diet supplemented with milk phospholipids concentrate. to the limits of detection by RIA) in leptin-deficient humans with a homozygous frame-shift mutation in the leptin gene (Montague et al., 1997). Even in the ob/ ob mice, there was still a tendency of compensation for the increase of adiposity by increasing leptin secretion. No statistically significant dietary treatment effect was observed for plasma leptin. Neither a time nor treatment effect was observed for plasma insulin and MCP-1 (Table 5). The plasma insulin level in the current study was similar to that in previous reports (Agardh et al., 1986). Inhibition of MCP-1 over-production is one of the efforts for ameliorating obesity-related comorbidities, such as insulin resistance (Panee, 2012). Dietary GG and PL in this study did not have a significant effect on MCP-1. Milk polar lipids did not affect plasma MCP-1 in C57BL/6J mice fed high-fat diets (Milard et al., 2019). There was no treatment effect on the fasting glucose and HOMA-IR at the end of the study (Table 5). The glucose and HOMA-IR values were similar to those reported previously (Moser et al., 2014). Taken together, the potential effect of milk PL/GG on insulin sensitivity in severe obesity still needs to be confirmed.

\section{Potential Confounding Factors and Limitations}

The dietary addition of GG $(0.02 \% \mathrm{wt} / \mathrm{wt})$ was determined according to a previous study where the dietary GG were observed to protect the TJ protein occludin in the intestinal mucosa from degradation during LPS-induced acute inflammation (Park et al., 2010). For practicability in the general dietary supplement, the GG was provided as a concentrate that also contains the milk PL. The amount of PL in the GG diet was about one-ninth of that in the PL diet. Most of the effects of the GG that were similar to those of the PL may be due to the PL content in the GG diet. The only unique effect of the GG compared with the PL in the present study was that the GG group had a higher occludin expression in the colon mucosa compared with the CO group. Many TJ proteins are involved with intestinal barrier integrity. The MFGM partially restored the expression of claudin- 1 on the apical surface of the intestinal villus in a neonatal rat model of necrotizing enterocolitis (Zhang et al., 2019). The regulation by milk polar lipids of other TJ proteins should now be explored such as claudins, tricellulin, and cingulin (Chelakkot et al., 2018). Therefore, the GG at the dose used in this study may not have any significant effect on lipid metabolism, gut permeability, and systemic inflammation in ob/ob mice when they are fed a moderately high-fat diet.

Two notable limitations of this study should be kept in mind during interpretation of the data. Multiple animal deaths indicate that the mice were under strong 
Table 6. Compared with control, dietary phospholipids (PL) mainly affected metabolism and inflammation, whereas dietary gangliosides $(\mathrm{GG})$ mainly affected tight junction protein expression in colon mucosa ${ }^{1}$

\begin{tabular}{lcc}
\hline Item & GG & PL \\
\hline Metabolism & & \\
Liver mass & - & $\downarrow$ \\
Liver cholesteryl ester and phosphatidylinositol & - & $\uparrow$ \\
Plasma free fatty acids, phospholipids, and sphingomyelin & - & $\uparrow$ \\
Liver expression of acetyl-CoA acetyltransferase 2 & & $\uparrow$ \\
Inflammation & & $\uparrow$ \\
Plasma IL-6 & $\uparrow$ & \\
Occludin in colon mucosa & $\downarrow$ & - \\
Zonula occludens-1 in colon mucosa & $\downarrow$ &
\end{tabular}

${ }^{1}$ GG group $=$ mice were fed the diet supplemented with milk gangliosides concentrate; PL group $=$ mice were fed the diet supplemented with milk phospholipids concentrate. $\uparrow=$ increase; $\downarrow=$ decrease; $-=$ no significant effect.

stress. The reduced sample size may have prevented the detection of certain differences among groups. However, despite the low sample size, this study found significant effects of milk polar lipids that should be explored further in follow-up experiments in severe obesity models and in humans.

\section{CONCLUSIONS}

In summary (Table 6), dietary supplementation of the milk PL reduced the liver mass and hepatic lipids but increased lipids in the plasma in the high-fat-fed ob/ob mice. The milk PL increased plasma sphingomyelin and IL-6 levels. The milk GG at the current dose affected TJ protein expression in the intestinal mucosa but did not have a significant effect on intestinal barrier integrity, lipid metabolism, or systemic inflammation in ob/ob mice. In conclusion, dietary supplementation of milk polar lipids may have limited beneficial effects on gut barrier integrity, systemic inflammation, and lipid metabolism in the context of severe obesity, which deserves further complementary investigations.

\section{ACKNOWLEDGMENTS}

This research was supported by the Western Dairy Center (Logan, UT). In addition, this research was supported by the Utah Agricultural Experiment Station, Utah State University, and approved as journal paper number UAES \#9196. The authors declare that there is no conflict of interest.

\section{REFERENCES}

Agardh, C. D., M. A. Lesniak, G. C. Gerritsen, and J. Roth. 1986. The influence of plasma insulin concentrations on tissue insulin levels in rodents: A study of the diabetic Chinese hamster and the ob/ob mouse. Metabolism 35:244-249.

Alessi, M. C., D. Bastelica, A. Mavri, P. Morange, B. Berthet, M. Grino, and I. Juhan-Vague. 2003. Plasma PAI-1 levels are more strongly related to liver steatosis than to adipose tissue accumulation. Arterioscler. Thromb. Vasc. Biol. 23:1262-1268.

Arrieta, M. C., K. Madsen, J. Doyle, and J. Meddings. 2009. Reducing small intestinal permeability attenuates colitis in the IL10 genedeficient mouse. Gut 58:41-48.

Bacon, B. R., C. H. Park, E. M. Fowell, and C. E. McLaren. 1984. Hepatic steatosis in rats fed diets with varying concentrations of sucrose. Fundam. Appl. Toxicol. 4:819-826.

Baron, C. B., and R. F. Coburn. 1984. Comparison of 2 copper reagents for detection of saturated and unsaturated neutral lipids by charring densitometry. J. Liq. Chromatogr. 7:2793-2801.

Bruewer, M., A. Luegering, T. Kucharzik, C. A. Parkos, J. L. Madara, A. M. Hopkins, and A. Nusrat. 2003. Proinflammatory cytokines disrupt epithelial barrier function by apoptosis-independent mechanisms. J. Immunol. 171:6164-6172.

Brun, P., I. Castagliuolo, V. Di Leo, A. Buda, M. Pinzani, G. Palu, and D. Martines. 2007. Increased intestinal permeability in obese mice: New evidence in the pathogenesis of nonalcoholic steatohepatitis. Am. J. Physiol. Gastrointest. Liver Physiol. 292:G518-G525.

Bullo, M., P. Casas-Agustench, P. Amigo-Correig, J. Aranceta, and J. Salas-Salvado. 2007. Inflammation, obesity and comorbidities: The role of diet. Public Health Nutr. 10(10A):1164-1172.

Cani, P. D., R. Bibiloni, C. Knauf, A. Waget, A. M. Neyrinck, N. M. Delzenne, and R. Burcelin. 2008. Changes in gut microbiota control metabolic endotoxemia-induced inflammation in high-fat diet-induced obesity and diabetes in mice. Diabetes 57:1470-1481.

Carter, H. E., and R. C. Gaver. 1967. Improved reagent for trimethylsilylation of sphingolipid bases. J. Lipid Res. 8:391-395.

Chelakkot, C., J. Ghim, and S. H. Ryu. 2018. Mechanisms regulating intestinal barrier integrity and its pathological implications. Exp. Mol. Med. 50:103.

Churchward, M. A., D. M. Brandman, T. Rogasevskaia, and J. R. Coorssen. 2008. Copper (II) sulfate charring for high sensitivity on-plate fluorescent detection of lipids and sterols: Quantitative analyses of the composition of functional secretory vesicles. J. Chem. Biol. 1:79-87.

Cohn, J. S., E. Wat, A. Kamili, and S. Tandy. 2008. Dietary phospholipids, hepatic lipid metabolism and cardiovascular disease. Curr. Opin. Lipidol. 19:257-262.

de Lima, V. M., C. P. de Oliveira, L. Y. Sawada, H. V. Barbeiro, E. S. de Mello, F. G. Soriano, V. A. Alves, S. H. Caldwell, and F. J. Carrilho. 2007. Yo jyo hen shi ko, a novel Chinese herbal, prevents nonalcoholic steatohepatitis in ob/ob mice fed a high fat or methionine-choline-deficient diet. Liver Int. 27:227-234.

Duan, R. D., and A. Nilsson. 2009. Metabolism of sphingolipids in the gut and its relation to inflammation and cancer development. Prog. Lipid Res. 48:62-72.

El Alwani, M., B. X. Wu, L. M. Obeid, and Y. A. Hannun. 2006. Bioactive sphingolipids in the modulation of the inflammatory response. Pharmacol. Ther. 112:171-183. 
Farhadi, A., A. Keshavarzian, J. Z. Fields, M. Sheikh, and A. Banan. 2006. Resolution of common dietary sugars from probe sugars for test of intestinal permeability using capillary column gas chromatography. J. Chromatogr. B Analyt. Technol. Biomed. Life Sci. 836:63-68.

Ferraris, R. P., and R. R. Vinnakota. 1995. Intestinal nutrient transport in genetically obese mice. Am. J. Clin. Nutr. 62:540-546.

Flurkey, K., J. Currer, and D. Harrison. 2007. Mouse models in aging research. Pages 637-672 in The Mouse in Biomedical Research. Vol. III. 2nd ed. J. Fox, M. Davisson, F. Quimby, S. Barthold, C. Newcomer, and A. Smith, ed. Academic Press, Cambridge, MA.

Folch, J., M. Lees, and G. H. Sloane Stanley. 1957. A simple method for the isolation and purification of total lipides from animal tissues. J. Biol. Chem. 226:497-509.

Genser, L., D. Aguanno, H. A. Soula, L. Dong, L. Trystram, K. Assmann, J. E. Salem, J. C. Vaillant, J. M. Oppert, F. Laugerette, M. C. Michalski, P. Wind, M. Rousset, E. Brot-Laroche, A. Leturque, K. Clement, S. Thenet, and C. Poitou. 2018. Increased jejunal permeability in human obesity is revealed by a lipid challenge and is linked to inflammation and type 2 diabetes. J. Pathol. 246:217-230

Guerville, M., A. Leroy, A. Sinquin, F. Laugerette, M. C. Michalski, and G. Boudry. 2017. Western-diet consumption induces alteration of barrier function mechanisms in the ileum that correlates with metabolic endotoxemia in rats. Am. J. Physiol. Endocrinol. Metab. 313:E107-E120.

Haslam, D. W., and W. P. James. 2005. Obesity. Lancet 366:11971209.

Iacono, A., G. M. Raso, R. B. Canani, A. Calignano, and R. Meli. 2011. Probiotics as an emerging therapeutic strategy to treat NAFLD: Focus on molecular and biochemical mechanisms. J. Nutr. Biochem. 22:699-711.

Iyer, A., D. P. Fairlie, J. B. Prins, B. D. Hammock, and L. Brown. 2010. Inflammatory lipid mediators in adipocyte function and obesity. Nat. Rev. Endocrinol. 6:71-82.

Kamili, A., E. Wat, R. W. Chung, S. Tandy, J. M. Weir, P. J. Meikle, and J. S. Cohn. 2010. Hepatic accumulation of intestinal cholesterol is decreased and fecal cholesterol excretion is increased in mice fed a high-fat diet supplemented with milk phospholipids. Nutr. Metab. (Lond.) 7:90.

Karagiannides, I., and C. Pothoulakis. 2008. Neuropeptides, mesenteric fat, and intestinal inflammation. Ann. N. Y. Acad. Sci. 1144:127-135.

Kupke, I. R., and S. Zeugner. 1978. Quantitative high-performance thin-layer chromatography of lipids in plasma and liver homogenates after direct application of 0.5-microliter samples to the silica-gel layer. J. Chromatogr. 146:261-271.

Kushwaha, R. S., A. Rosillo, R. Rodriguez, and H. C. McGill Jr.. 2005. Expression levels of ACAT1 and ACAT2 genes in the liver and intestine of baboons with high and low lipemic responses to dietary lipids. J. Nutr. Biochem. 16:714-721.

Laugerette, F., M. Alligier, J. P. Bastard, J. Drai, E. Chanseaume, S. Lambert-Porcheron, M. Laville, B. Morio, H. Vidal, and M. C. Michalski. 2014. Overfeeding increases postprandial endotoxemia in men: Inflammatory outcome may depend on LPS transporters LBP and sCD14. Mol. Nutr. Food Res. 58:1513-1518.

Laugerette, F., J. P. Furet, C. Debard, P. Daira, E. Loizon, A. Geloen, C. O. Soulage, C. Simonet, J. Lefils-Lacourtablaise, N. BernoudHubac, J. Bodennec, N. Peretti, H. Vidal, and M. C. Michalski. 2012. Oil composition of high-fat diet affects metabolic inflammation differently in connection with endotoxin receptors in mice. Am. J. Physiol. Endocrinol. Metab. 302:E374-E386.

LeBlanc, M. J., S. Brunet, G. Bouchard, T. Lamireau, I. M. Yousef, V. Gavino, E. Levy, and B. Tuchweber. 2003. Effects of dietary soybean lecithin on plasma lipid transport and hepatic cholesterol metabolism in rats. J. Nutr. Biochem. 14:40-48.

Lecomte, M., L. Couedelo, E. Meugnier, P. Plaisancie, M. Letisse, B. Benoit, L. Gabert, A. Penhoat, A. Durand, G. Pineau, F. Joffre, A. Geloen, C. Vaysse, F. Laugerette, and M. C. Michalski. 2016. Dietary emulsifiers from milk and soybean differently impact adi- posity and inflammation in association with modulation of colonic goblet cells in high-fat fed mice. Mol. Nutr. Food Res. 60:609-620.

Meddings, J. B., and I. Gibbons. 1998. Discrimination of site-specific alterations in gastrointestinal permeability in the rat. Gastroenterology 114:83-92.

Milard, M., F. Laugerette, A. Durand, C. Buisson, E. Meugnier, E. Loizon, C. Louche-Pelissier, V. Sauvinet, L. Garnier, S. Viel, K. Bertrand, F. Joffre, D. Cheillan, L. Humbert, D. Rainteau, P. Plaisancie, L. B. Bindels, A. M. Neyrinck, N. M. Delzenne, and M. C. Michalski. 2019. Milk polar lipids in a high-fat diet can prevent body weight gain: Modulated abundance of gut bacteria in relation with fecal loss of specific fatty acids. Mol. Nutr. Food Res. 63:e1801078.

Montague, C. T., I. S. Farooqi, J. P. Whitehead, M. A. Soos, H. Rau, N. J. Wareham, C. P. Sewter, J. E. Digby, S. N. Mohammed, J. A. Hurst, C. H. Cheetham, A. R. Earley, A. H. Barnett, J. B. Prins, and S. O'Rahilly. 1997. Congenital leptin deficiency is associated with severe early-onset obesity in humans. Nature 387:903-908.

Moreira, A. P., T. F. Texeira, A. B. Ferreira, C. Peluzio Mdo, and C. Alfenas Rde. 2012. Influence of a high-fat diet on gut microbiota, intestinal permeability and metabolic endotoxaemia. Br. J. Nutr. 108:801-809.

Moser, C., S. P. Vickers, R. Brammer, S. C. Cheetham, and J. Drewe. 2014. Antidiabetic effects of the Cimicifuga racemosa extract $\mathrm{Ze}$ 450 in vitro and in vivo in ob/ob mice. Phytomedicine 21:1382 1389 .

Moshfegh, A., J. Goldman, J. Ahuja, D. Rhodes, and R. LaComb. 2009. What We Eat in America, NHANES 2005-2006: Usual Nutrient Intakes from Food and Water Compared to 1997 Dietary Reference Intakes for Vitamin D, Calcium, Phosphorus, and Magnesium. USDA Agricultural Research Service, Washington, DC.

Nestel, P. J., N. Mellett, S. Pally, G. Wong, C. K. Barlow, K. Croft, T. A. Mori, and P. J. Meikle. 2013. Effects of low-fat or full-fat fermented and non-fermented dairy foods on selected cardiovascular biomarkers in overweight adults. Br. J. Nutr. 110:2242-2249.

Noh, S. K., and S. I. Koo. 2004. Milk sphingomyelin is more effective than egg sphingomyelin in inhibiting intestinal absorption of cholesterol and fat in rats. J. Nutr. 134:2611-2616.

Norris, G. H., C. Jiang, J. Ryan, C. M. Porter, and C. N. Blesso. 2016. Milk sphingomyelin improves lipid metabolism and alters gut microbiota in high fat diet-fed mice. J. Nutr. Biochem. 30:93-101.

Norris, G. H., C. M. Porter, C. Jiang, C. L. Millar, and C. N. Blesso. 2017. Dietary sphingomyelin attenuates hepatic steatosis and adipose tissue inflammation in high-fat-diet-induced obese mice. J. Nutr. Biochem. 40:36-43.

Oishi, K., N. Ohkura, M. Wakabayashi, H. Shirai, K. Sato, J. Matsuda, G. Atsumi, and N. Ishida. 2006. CLOCK is involved in obesityinduced disordered fibrinolysis in ob/ob mice by regulating PAI-1 gene expression. J. Thromb. Haemost. 4:1774-1780.

Panee, J. 2012. Monocyte chemoattractant protein 1 (MCP-1) in obesity and diabetes. Cytokine 60:1-12.

Park, E. J., M. Suh, B. Thomson, D. W. Ma, K. Ramanujam, A. B. Thomson, and M. T. Clandinin. 2007. Dietary ganglioside inhibits acute inflammatory signals in intestinal mucosa and blood induced by systemic inflammation of Escherichia coli lipopolysaccharide. Shock 28:112-117.

Park, E. J., A. B. Thomson, and M. T. Clandinin. 2010. Protection of intestinal occludin tight junction protein by dietary gangliosides in lipopolysaccharide-induced acute inflammation. J. Pediatr. Gastroenterol. Nutr. 50:321-328.

Peterson, C. Y., T. W. Costantini, W. H. Loomis, J. G. Putnam, P. Wolf, V. Bansal, B. P. Eliceiri, A. Baird, and R. Coimbra. 2010. Toll-like receptor-4 mediates intestinal barrier breakdown after thermal injury. Surg. Infect. (Larchmt.) 11:137-144.

Pham Ba, V. A., Y. M. Han, Y. Cho, T. Kim, B. Y. Lee, J. S. Kim, and S. Hong. 2018. Modified floating electrode-based sensors for the quantitative monitoring of drug effects on cytokine levels related with inflammatory bowel diseases. ACS Appl. Mater. Interfaces 10:17100-17106. 
Rogers, T. S., E. Demmer, N. Rivera, E. R. Gertz, J. B. German, J. T. Smilowitz, A. M. Zivkovic, and M. D. Van Loan. 2017. The role of a dairy fraction rich in milk fat globule membrane in the suppression of postprandial inflammatory markers and bone turnover in obese and overweight adults: An exploratory study. Nutr. Metab. (Lond.) 14:36.

Samad, F., K. D. Hester, G. Yang, Y. A. Hannun, and J. Bielawski. 2006. Altered adipose and plasma sphingolipid metabolism in obesity: A potential mechanism for cardiovascular and metabolic risk. Diabetes 55:2579-2587.

Schnabl, K. L., M. Larcelet, A. B. Thomson, and M. T. Clandinin. 2009. Uptake and fate of ganglioside GD3 in human intestinal Caco-2 cells. Am. J. Physiol. Gastrointest. Liver Physiol. 297:G52G59.

Shimizu, K., T. Ida, H. Tsutsui, T. Asai, K. Otsubo, and N. Oku. 2010. Anti-obesity effect of phosphatidylinositol on diet-induced obesity in mice. J. Agric. Food Chem. 58:11218-11225.

Singhal, N. S., R. T. Patel, Y. Qi, Y. S. Lee, and R. S. Ahima. 2008. Loss of resistin ameliorates hyperlipidemia and hepatic steatosis in leptin-deficient mice. Am. J. Physiol. Endocrinol. Metab. 295:E331-E338.

Snow, D. R., R. Jimenez-Flores, R. E. Ward, J. Cambell, M. J. Young, I. Nemere, and K. J. Hintze. 2010. Dietary milk fat globule membrane reduces the incidence of aberrant crypt foci in Fischer-344 rats. J. Agric. Food Chem. 58:2157-2163.

Snow, D. R., R. E. Ward, A. Olsen, R. Jimenez-Flores, and K. J. Hintze. 2011. Membrane-rich milk fat diet provides protection against gastrointestinal leakiness in mice treated with lipopolysaccharide. J. Dairy Sci. 94:2201-2212.

Stefano, J. T., C. P. de Oliveira, M. L. Correa-Giannella, V. M. de Lima, S. V. de Sa, E. P. de Oliveira, E. S. de Mello, D. GiannellaNeto, V. A. Alves, and F. J. Carrilho. 2007. Nonalcoholic steatohepatitis (NASH) in ob/ob mice treated with yo jyo hen shi ko (YHK): Effects on peroxisome proliferator-activated receptors (PPARs) and microsomal triglyceride transfer protein (MTP). Dig. Dis. Sci. 52:3448-3454.

Teixeira, T. F., N. C. Souza, P. G. Chiarello, S. C. Franceschini, J. Bressan, C. L. Ferreira, and M. D. Peluzio. 2012. Intestinal permeability parameters in obese patients are correlated with metabolic syndrome risk factors. Clin. Nutr. 31:735-740.
Vors, C., G. Pineau, J. Drai, E. Meugnier, S. Pesenti, M. Laville, F. Laugerette, C. Malpuech-Brugere, H. Vidal, and M. C. Michalski. 2015. Postprandial endotoxemia linked with chylomicrons and lipopolysaccharides handling in obese versus lean men: A lipid doseeffect trial. J. Clin. Endocrinol. Metab. 100:3427-3435.

Wallace, T. M., J. C. Levy, and D. R. Matthews. 2004. Use and abuse of HOMA modeling. Diabetes Care 27:1487-1495.

Wang, X., A. Spandidos, H. Wang, and B. Seed. 2012. PrimerBank: A PCR primer database for quantitative gene expression analysis, 2012 update. Nucleic Acids Res. 40:D1144-D1149.

Wat, E. S. Tandy, E. Kapera, A. Kamili, R. W. Chung, A. Brown, M. Rowney, and J. S. Cohn. 2009. Dietary phospholipid-rich dairy milk extract reduces hepatomegaly, hepatic steatosis and hyperlipidemia in mice fed a high-fat diet. Atherosclerosis 205:144-150.

Weisberg, S. P., D. McCann, M. Desai, M. Rosenbaum, R. L. Leibel, and A. W. Ferrante. 2003. Obesity is associated with macrophage accumulation in adipose tissue. J. Clin. Invest. 112:1796-1808.

Wrenn, S. M. Jr., J. S. Parks, F. W. Immermann, and L. L. Rudel. 1995. ACAT inhibitors CL 283,546 and CL 283,796 reduce LDL cholesterol without affecting cholesterol absorption in African green monkeys. J. Lipid Res. 36:1199-1210.

Xu, J., S. R. Kulkarni, L. Y. Li, and A. L. Slitt. 2012. UDP-glucuronosyltransferase expression in mouse liver is increased in obesity- and fasting-induced steatosis. Drug Metab. Dispos. 40:259-266.

Yamaki, T., M. Uchida, Y. Kuwahara, Y. Shimazaki, K. Ohtake, M. Kimura, H. Uchida, J. Kobayashi, M. Ogihara, Y. Morimoto, and H. Natsume. 2013. Effect of poly-L-arginine on intestinal absorption of hydrophilic macromolecules in rats. Biol. Pharm. Bull. $36: 496-500$.

Zhang, D., J. Wen, J. Zhou, W. Cai, and L. Qian. 2019. Milk fat globule membrane ameliorates necrotizing enterocolitis in neonatal rats and suppresses lipopolysaccharide-induced inflammatory response in IEC-6 enterocytes. JPEN J. Parenter. Enteral Nutr. https://doi.org/10.1002/jpen.1496.

Zhou, A. L., K. J. Hintze, R. Jimenez-Flores, and R. E. Ward. 2012. Dietary fat composition influences tissue lipid profile and gene expression in Fischer-344 rats. Lipids 47:1119-1130. 